Western University

Scholarship@Western

Education Publications

Education Faculty

2009

\title{
Practising Mathematics Teacher Education: Expanding The Realm of Possibilities
}

Uwe Gellert

Freie Universita"t Berlin, Germany

S. Amato

M. Bairral

L. Zanette

I. Bloch

See next page for additional authors

Follow this and additional works at: https://ir.lib.uwo.ca/edupub

Part of the Education Commons

Citation of this paper:

Gellert U. et al. (2009) Practising Mathematics Teacher Education: Expanding The Realm of Possibilities. In: Even R., Ball D.L. (eds)

The Professional Education and Development of Teachers of Mathematics. New ICMI Study Series, vol 11. Springer, Boston, MA 


\section{Authors}

Uwe Gellert, S. Amato, M. Bairral, L. Zanette, I. Bloch, George Gadanidis, Immaculate Kizito Namukasa, G. Krummheuer, B. Grevholm, C. Bergsten, D. Miller, A. Peter-Koop, B. Wollring, J. Proulx, L. M. Rosu, B.

Arvold, and N. Sayac 


\section{Practising Mathematics Teacher Education: Expanding The Realm of Possibilities}

Uwe Gellert, Freie Universität Berlin, Germany, and S. Amato, M. Bairral, L. Zanette, I. Bloch, G. Gadanidis, I. Namukasa, G. Krummheuer, B. Grevholm, C. Bergsten, D. Miller, A. Peter-Koop, B. Wollring, J. Proulx, L. M. Rosu, B. Arvold, N. Sayac

\section{Introduction}

It is often said that student teachers' underlying beliefs of what mathematics consists of and how it should be taught are restricted in two ways. On the one hand, future elementary teachers in general use only weak mathematical conceptions, which often do not help them to realise their educational ambitions. On a general educational level, many of these students advocate discovery learning and collective problem solving, but when it comes down to the mathematical activities that have to be prepared, their experience of "traditional" school mathematics is of little help. On the other hand, future (higher) secondary teachers mostly are very well prepared with respect to formal academic mathematics when entering mathematics education programmes, either because they have already passed a mathematical formation at university or because 
their teacher education programmes emphasise the study of

academic mathematics and not of educational or didactical modules.

Being socialised as mathematicians, and not as mathematics

teachers, these future teachers often lack the experience of how to convert formal mathematics into school mathematical activities.

For both future teachers, elementary as well as secondary, building conceptions of mathematically rich and cognitively and socially stimulating school mathematical activities is at the heart of the process of their professional formation. Mathematics teacher education, in that sense, provides opportunities for future mathematics teachers to expand the realm of their possibilities.

However, the title of this chapter carries a second meaning. By presenting examples from the practice of teacher education, we aim at expanding the realm of possibilities for and within programmes of mathematics teacher education. These possibilities can be seen, again, as activities: by adapting and transforming the diverse examples presented here, teacher educators may organise new and different activities for future teachers to actively develop their professional knowledge.

In line with this view, this chapter does not intend to propagate "best practices". "Best practices" strive towards generating "perfect teachers", thus reflecting a technocratic cause-effect mentality, or a 
"training" mindset, in the project of achieving the perfect image of a mathematics teacher. However, the outcomes of any mathematics teacher education programme, or of single courses and activities therein, are much more diverse and unpredictable than might be expected: the perceptions, interpretations, and uses are going to be different for each student teacher (Proulx, 2005).

This chapter, instead, tries to widen the horizon of programmes and activities in mathematics teacher education by presenting stimulating examples from diverse countries and teacher education cultures. First, these examples may directly contribute to an enrichment of mathematics teacher education practices. Second, and reflectively, the diversity of the examples presented here may provoke a re-consideration of the objectives of the mathematics teacher education programmes in use.

The examples from teacher education practice to be presented in this chapter have been grouped into four areas, thus reflecting their main purposes for the education of future mathematics teachers:

- Activating the understanding of school mathematics

- Enhancing the communication of mathematical ideas

- Using information and communication technology (ICT) in mathematics teacher education

- Studying classroom practice 
While this chapter draws to some extent from the existing body

of literature about teacher education practices, the examples displayed in boxes were all presented and discussed at the 15th ICMI Study. The boxes are excerpts from the study conference papers. This chapter does not scrutinise these examples analytically but, instead, offers a bouquet of activities and experiences, thus trying to fire the reader's imagination.

It should be noted that within the respective conference papers most of these examples have been discussed and used within a research context. This research context is rather ignored in the chapter on hand.

\section{Activating the Understanding of School Mathematics}

School mathematics can be regarded as an autonomous body of knowledge. It is not a simplistic form of academic mathematics. It is not striving exclusively for symbolic abstraction and rigour. In order to be meaningful for the majority of the students, it tries to construct visual representations for mathematical concepts and relations. Whereas, for instance, academic mathematics defines mathematical concepts symbolically and tries to avoid redundant formulation, school mathematical knowledge of a mathematical concept comprises the diverse representations of the concept as well as the 
translations between them.

One focus of mathematics teacher education practices is to activate the student teachers' understanding of school mathematics by involving them in school mathematical activities of translation between different representations. This proves to be useful for both future primary school teachers (Amato, 2005; Gadanidis \& Namukasa, 2005; Peretz, 2006) and future secondary-school teachers (Bloch, 2005).

Amato $(2004,2005)$ reports that although student teachers generally correctly perform the multiplication of large numbers, only a few of them use the concept of place value to explain why numbers move over in the partial products:

The student teachers were asked to explain the reason for leaving blank the units' place of the second addend in the multiplication algorithm for $45 \times 123$. The most frequent type of explanation was related to place value, but it did not involve much conceptual understanding: "Because I am now working with the tens' place, then I write the next number under the tens". Eight student teachers wrote about calculating 4 times 123 and none wrote about calculating 40 times 123 . Two student teachers said it was to make the result bigger. The ideas presented by a few student teachers were thought to have the potential to develop the belief that mathematics is an irrational subject: "I would say that the place is reserved for the + [addition] sign" (Amato, 2005). 
Amato uses school children's activities as a strategy to activate

student teachers' understanding of school mathematics, as shown in the following example:

Versatile representations (Amato, 2004), like the area representation for multiplication, were used in activities in order to represent together two or more related concepts and operations and so to make their relationships clear. The student teachers were first given some practice in using the area representation with concrete materials [a plane version of Dienes blocks, Fig. 1.1.3.1] and later they were asked to interpret and draw area diagrams [Fig. 1.1.3.2].

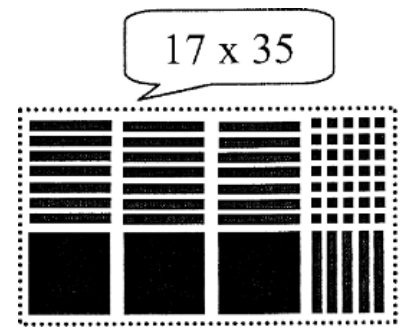

Fig. 1.1.3.1 Plane version of Dienes blocks

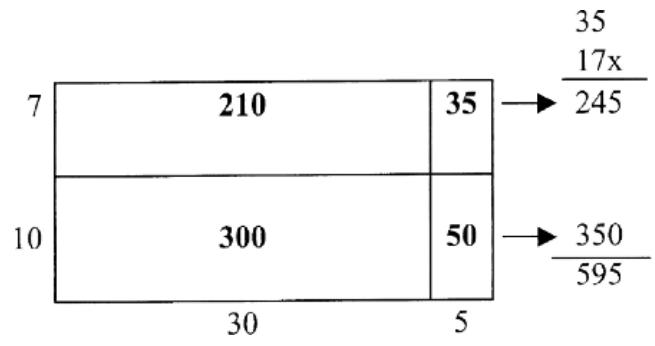

Fig. 1.1.3.2 Area diagram 
From her experience with this kind of activity Amato concludes that the student teachers' understanding of the area representation of multiplication is related to an explicit teaching of the conventions used in those representations. Accordingly, she introduces more activities for multiplication of two-digit numbers:

In order to help student teachers understand the conventions used in the area representation, an analogy was made with constructing a wall with big bricks (hundreds), medium bricks (tens) and small bricks (units). The student teachers were asked which they thought it would be quicker to construct a wall: (a) to use as many bigger bricks as possible or (b) to start the construction by using small bricks? Before using the "bricks" to construct the wall they were asked to use the strips (tens) and little squares (units) as "rulers" to measure the base and height of the wall [Fig. 1.1.3.3]. After they finished constructing the wall they were asked to remove the rulers and verbalise the four partial multiplication sums $(7 \times 5,7 \times 30,10 \times 5,10 \times$ 30).

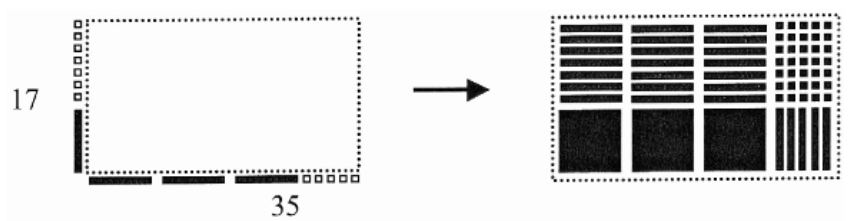

Fig. 1.1.3.3 Base and height of the wall

Gadanidis and Namukasa (2005) provide another example of how primary-school student teachers can get involved in school children's mathematical activities. They design activities to be "interesting and challenging enough to capture their [future primary teachers] interest and imagination and to offer the potential for mathematical insight and surprise." They use a variety of school mathematics problems and situations for exploration, all being problem-solving tasks that 
were non-routine to the student teachers, for example:

One of the problems explored the equation $+_{-}=10$. Pre-service teachers rolled a die to get the first number and then calculated the second number. They wrote the pairs of numbers in table and in ordered pair form, and plotted the ordered pairs on a grid. We repeated this for $+_{-}=6$ and $+_{-}=4$.

Some pre-service teachers expressed surprise that the ordered pairs lined up [Fig. 1.1.3.4]. "I had the 'aha' feeling when I saw the diagonal line pattern on the graph. That was my favourite part." Pre-service teachers also noticed that the graph of_+_ $=4$ could be used as a visual proof of $6+(-2)=4$ and $5+(-1)=4$. That is, $(6,-2)$ and $(5,-1)$ line up with $(4,0),(3,1),(2,2)$ and

$(1,3)$. They also explored equations whose graphs were not parallel to the ones in [Fig. 1.1.3.4] and whose graphs were not straight lines. Such mathematical connections appeared to be pleasing to the pre-service teachers. "I loved the adding/graphing we did and how you should take problems and branch out ... it really makes something in my mind click."

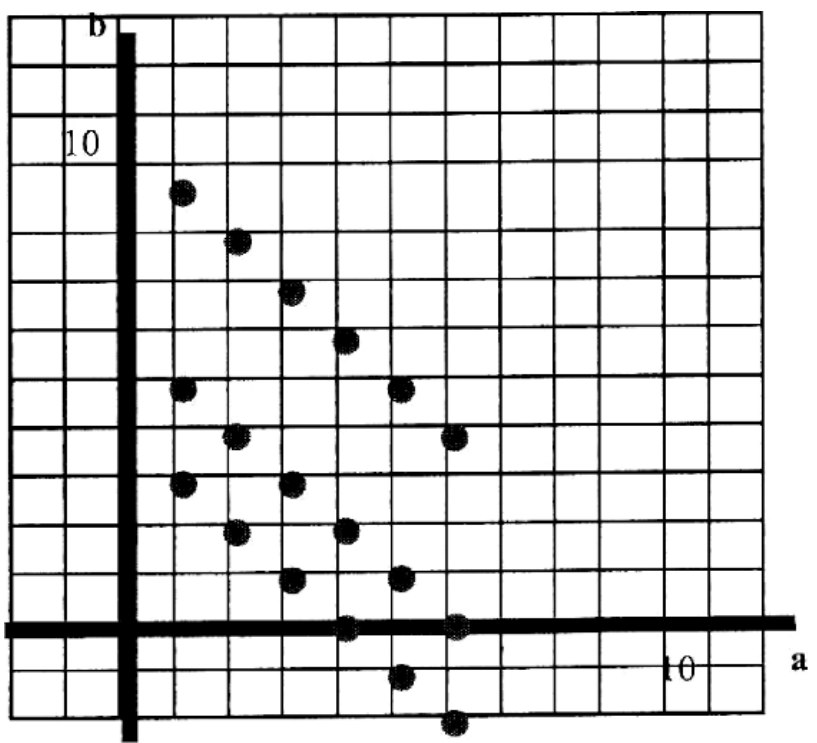

$$
a+b=10, a+b=6 \text { anda }+b=4
$$

Fig. 1.1.3.4 Ordered pairs lined up 
While it may appear as a straightforward method to involve future primary-school teachers in activities that on the one hand intend to activate their understanding of school mathematics and, on the other hand, may serve as a blueprint for future teaching of primaryschool mathematics, this is not obviously the case for novice secondary mathematics teachers. In many countries, these future teachers have received a mathematical formation similar to that of a mathematician before entering courses in mathematics education. Bloch (2005) points to the fact that students "often get a very formal conception of mathematics during their university courses. For them, a theorem has to get a proof, but no justification in terms of problem solving, it is seen as a part of a mathematical theory which its own justification." This socialisation into academic mathematics is completed by a very specific way of knowledge transfer. Through their mathematical formation, future secondary mathematics teachers get used to the idea that mathematics teaching has to be done by a teacher in front of the students and that the teacher tells the mathematical laws and explains mathematical algorithms. As Bloch (2005) observes, student teachers "have no idea that the mathematical law could be understood, overall, considering that only elementary mathematics are in question at that level. The 
mathematical formalism seems transparent to them. They are

accustomed to take what the mathematics teacher said at University

for granted and cannot imagine any other behaviour from the students

in their own classes."

From this observation, Bloch draws the necessity to offer new

situations to make their knowledge of school mathematics evolve also

to the novice secondary teachers and new activities to get them to

know what mathematical interactions with their students are. For

example, Bloch introduces a "grid game":

A situation to introduce the product of vectors by real numbers has been tested with novice teachers. It consists of a communication about collinear vectors and decomposition in a basis, whose support is a grid. The direct game simply consists in calculating sums of vectors, and associating them to the correct points, as usually done. This first direct game institutes a heuristic milieu, the milieu where students can get the technique and the basic strategy: they discover that if they multiply a vector by a number they can start from a point and reach another point. The type of instruction at this phase is: let $\mathrm{A}$ be a point of the plane, $\mathrm{V}$ a given vector; place the point $\mathrm{B}$ such as $\mathrm{AB}=\mathrm{V}$.

The inverse game has got two phases itself: In Phase 1 the game aims to find points by doing the product of one given vector by numbers. What is at stake in this Phase 1 is the way, how students relate real numbers and lines in the plane. Students work in groups in which there are two emitters and two recipients. Emitters - who dispose of a schema with points that are unknown to the recipients - have to send a message to their corresponding recipients to make them find the unknown points [see Fig. 1.1.3.5].

The second phase works with the functionality of a two vectors basis in the plane. It is a communication game too, but in a two dimensional system (a basis). In Phase 2 students have to find that, two non colinear vectors and a point being given, by sum and product, one can reach unknown points [see Figs. 1.1.3.6 and 1.1.3.7]. If reaching every point is not effectively possible, restraining to integer coefficients is not enough to understand the generality of the rule: the students have to do the calculation in some non trivial cases. The main objective is to make students understand the rule of how a vector basis operates, before they are told the formal expression of this rule. For future teachers, the situation has the objective of understanding by action that with a basis of two vectors they can reach every point of the affine plane; this is a pragmatic proof of the 
functionality of the concept of basis; and, it makes student teachers discover that pragmatic proofs are not evident even when a formal proof is wellknown. For that purpose, it is necessary to let young teachers effectively reach some points with real coefficients or rational numbers (Bloch, 2005).

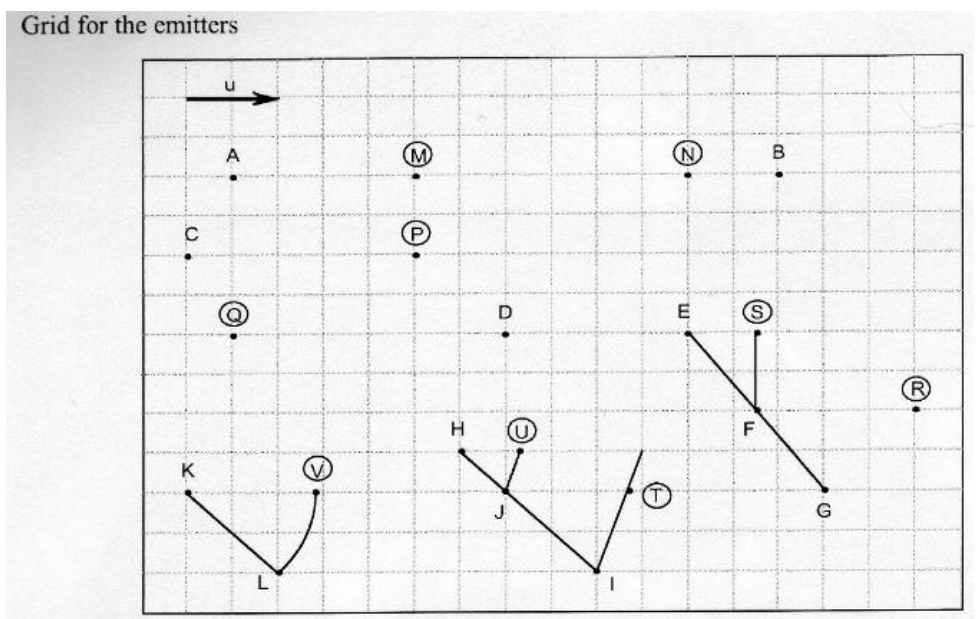

The other team has got the same grid as you, but with only the points A to L and the vector $\mathbf{u}$. Send them messages to place the points M to V. You're not allowed to tell geometric descriptions in your messages, that must contain only

Fig. 1.1.3.5 Phase 1

Insightful experience of school mathematics is an important starting point for the development of teachers' perceptions and classroom practice. These examples react on the difficulties primary and secondary mathematics teachers face when introducing standard mathematical concepts and procedures in the classroom. They demonstrate that school mathematical activities, which in all three examples are essentially related to the representational character of school mathematics, need to be regarded as an important pillar of any teacher education programme. 


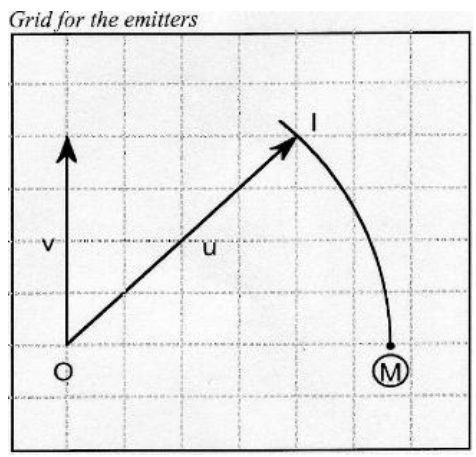

The other team has got the same grid as you, but with only the point $\mathrm{O}$ and the vectors $\mathrm{u}$ and $\mathrm{v}$. Send them a message to place the point $\mathrm{M}$. It is on the circle $(\mathrm{O}, \mathrm{OI})$, and on a straight line orthogonal to v. But you are not allowed to tell it in your message that must contain only $\mathrm{O}, \mathrm{u}, \mathrm{v}$ and numbers.

Fig. 1.1.3.6 Phase 2, with circle

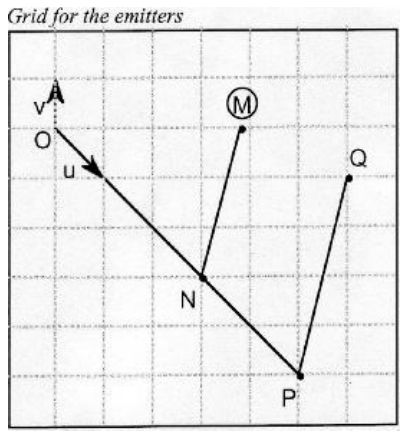

The other team has got the same grid as you, but with only the point $\mathrm{O}$ and the vectors $u$ and $v$. Sent them a message to place the point $M$. It is at a place so that (MN) // (PQ) and the points N, P, Q are exactly at the crosses of the grid. But you are not allowed to tell it in your message that must contain only $\mathrm{O}, \mathrm{u}, \mathrm{v}$ and numbers.

Fig. 1.1.3.7 Phase 2, with parallels

\section{Enhancing the Communication of Mathematical Ideas}

The community of researchers in mathematics education broadly accepts the claim that language matters in the mathematics classroom. Many facets of this issue have been investigated (e.g., 
Bauersfeld, 1995; Kieran, Forman, \& Sfard, 2002; Pimm, 1987).

However, with respect to the preparation of mathematics teachers, this important issue is frequently neglected or, not much better, treated implicitly, based on the conviction that a language to express mathematical ideas develops automatically from mathematical activity. This point of view is theoretically na"ive with respect to the pupils' learning of mathematics. It is counterproductive with respect to future teachers learning to teach mathematics. Both Grevholm and Bergsten (2005) and Peter-Koop and Wollring (2005) point to the fact that the development of a mathematics teacher's professional language is a critical issue for mathematics teacher education. Preservice teachers should be aware that the creation of a mathematical language is an essential part of mathematical activities.

This creation, indeed, is not a simple and automatically occurring phenomenon. According to Bernstein (1996) everyday knowledge is context dependent and segmentally organised and consistent within each segment, but segments overlap and knowledge organisations often do not match. The same holds for everyday activities and everyday language. In contrast, school mathematics is systematically principled and hierarchically organised. It requires the development of a mathematically 
should be explicitly reflected within teacher education practice. This paragraph shows two examples of explicit enhancing of the communication of mathematical ideas and concepts in mathematics teacher education.

Peter-Koop and Wollring (2005) refer to common classroom experience as well as to psychological research when arguing that “especially with young children, (mathematics related) action seems to precede the ability to express one's own (mathematics related) thoughts, ideas and strategies in words". They conclude that the development and the use of non-verbal language, which reflect mathematics- related actions, are substantial for improving the process of teaching and learning. This is particularly important for "the communication about shape, number and structure in the primary mathematics classroom. From our point of view, mathematics yields special communication platforms with respect to functional communication-especially through the exploration of various iconic forms of articulation and communication, such as children's drawings or folding posters". Peter- Koop and Wollring demonstrate that future teachers as well as primary school pupils can successfully develop (mostly) non-verbal instructions for folding a special paper star: 
The example illustrates how different forms of iconic articulation can support the communication of mathematical ideas. The context of the two examples below is the exploration of geometrical concepts through paper folding activities. The pictures show two "folding posters" (in German: "Faltplakate") designed by fourth graders [Fig. 1.1.3.8] and student teachers from a geometry course [Fig. 1.1.3.9]. The idea was to provide a folding instruction for second graders that would work without further oral explanation. The two

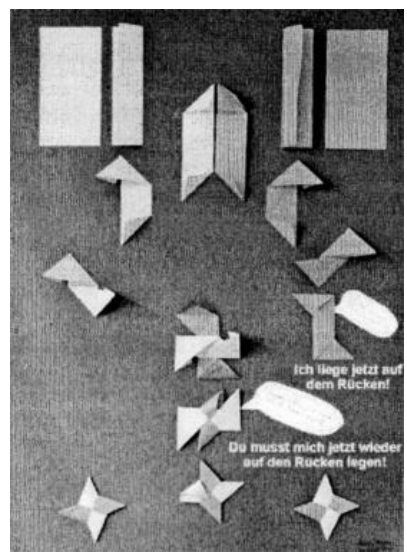

Fig. 1.1.3.8 Faltplakat designed by fourth graders

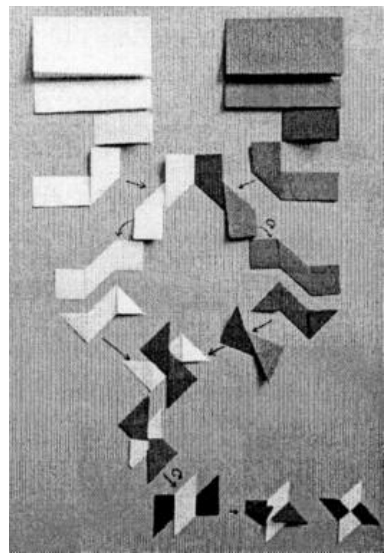

Translation of the pupils' comments in Figure 1.1.3 h: "Now I am lying on my back!" "You have to put me on my back again!"

Fig. 1.1.3.9 Faltplakat designed by student teachers 
folding posters illustrate in how far the fourth graders as well as the student teachers communicate key construction ideas which are related to the special properties of the object - in this case a star that is made out of two congruent but symmetrically opposite parts (Peter-Koop \& Wollring, 2005).

Grevholm and Bergsten (2005) report on a development project in mathematics teacher education that aims at explicitly developing a mathematics teachers' professional language. In their project, groups of four to five student teachers work collaboratively, and without interference from teacher educators, with core concepts in mathematics. These future teachers are asked to produce a shared and agreed result in written form. The results from the various groups are compared, and thereafter a videotape from one group's collaborate activity is jointly discussed. The focus of this reflection is on the language that is used to explore and explain the mathematical tasks. According to Grevholm and Bergsten (2005), it is highly important to create open, explorative tasks with focus on core concepts of school mathematics "that promote mathematical discussion and reasoning in the group work of student teachers". An example of such a mathematical task, with the core concepts of mode, median, and average, is presented below: 
The thirteen employed have an average salary of 166555 SEK per month. The mode (called "typvärde," typical value in Swedish) for a monthly salary is 1 million SEK.

The reporter asks how big the median salary is.

"Yes, it is 16000 SEK per month but that is not so interesting in this connection," claims the director.

Question 1

Does the director tell the truth? Can the facts given about the salaries really be true? What could the salary pattern look like?

Question 2

Three different statistical measures are mentioned in the text. When is one and when the other measure relevant to use? How did the director choose to measure and why do you think he did so?

Question 3

How would you plan a teaching sequence about statistical measures for pupils in Years 5 and 9 respectively? Make a draft plan that you think is good and explain why you have chosen this model. What knowledge about statistical measures do you consider important for the pupils?

Question 4

What did you learn from this exercise? How does it differ from earlier tasks that you have solved about statistical measures? Can pupils in compulsory school solve this type of tasks? Do you find such tasks in the textbooks?

\section{Material}

Text from the terminology book Matematikterminologi $i$ skolan, quotations from the compulsory school mathematics curriculum and mathematics textbooks for years 4-9 (Grevholm \& Bergsten, 2005).

\section{Using Information and Communication Technology}

\section{in Mathematics Teacher Education}

Information and communication technology (ICT) is used within mathematics teacher education courses for three purposes, which can be separated analytically. First, ICT is a means to facilitate student teachers in learning to teach mathematics. For instance, student teachers can be offered access to databanks of videotaped classroom interaction or to platforms for joining "virtual communities" (Bairral 
$\&$ Zanette, 2005). Second, ICT can be treated as a teacher's tool to

teach mathematics to schoolchildren. Third, ICT can be regarded as being an integral part of school mathematics. In this last sense, it is an aim of mathematics teacher education to accustom student teachers to the view that innovative mathematics education is ICT based: "ICT is not just a simple auxiliary tool. It is an essential technological element that shapes the social environment, including mathematics teaching. Therefore, it influences the mathematics teacher's evolution regarding professional knowledge and identity" (da Ponte, Oliveira, \& Varandas, 2002, p. 113). In the praxis of mathematics teacher education the three approaches are not strictly separated. Accordingly, Miller (2005), who is making use of metaphors from the fields of ecology and anthropology, speaks of an "ICT-rich mathematical education environment" and an "ICT culture". He starts from the premise that in order to meet the ICT standards set by official (governmental or state) regulations preservice teachers should be introduced into ICT-rich mathematical education environments. Miller (2005) provides a description of a rather extensive and comprehensive ICT environment in a British university, in which pre-service teachers learn to teach ICT-based school mathematics. 


\section{An ICT-rich mathematical-education environment}

"Students are quick to adopt the current climate of opinion about the role of new technologies that they see exemplified by their own subject teachers." To this end the mathematics course design not only allows the teacher educators to act as role models but also looks to set an ICT culture providing:

- over $90 \%$ of the sessions where the use of an interactive whiteboard is central to learning

- ICT applications such as spreadsheets, graph plotters and geometry programmes that are integrated "seamlessly" into sessions

- regular timetabled subject-based ICT sessions

- a requirement that all students will have used ICT at least twice with a class or small group of pupils on the first 7-week teaching practice

- a subject-based ICT assignment

- a form to monitor the student's use of ICT with pupils

- a laptop computer for a group of students to use in school with pupils

- CD-ROM of resources that includes ICT training resources

- interactive whiteboard specific software, user guides and a tutorial programme that can be followed to learn how to use an interactive white- board

- lesson materials that incorporate ICT and/or interactive whiteboard use To assure that all our students can demonstrate that they have ICT as a "strength" we have linked aspects of ICT knowledge, understanding and skills with the formal assessment process (Miller, 2005).

\section{Among these conditions for ICT-rich environments in}

mathematics teacher education, Miller (2005) identifies four features

of ICT in mathematics courses that are key to the British situation:

basic support for cooperative work, the use of the interactive

whiteboard, spreadsheet skills, and the use of ICT in the teaching of school mathematics: 


\section{Basic support for cooperative work}

We require that our students share work and ideas, so we have placed them in eight groups. Within these groups they have to: solve a mathematical problem and produce a solution using, for example, PowerPoint; design a number of posters to illustrate the mathematics possible in a topic, such as trees or jewellery; produce a resource and lesson plan related to citizenship in mathematics; and provide a review of a website useful for the teaching and learning of mathematics. To facilitate sharing we use a free-access website, Basic Support for Cooperative Work (BSCW: http://bscw.fit.fraunhofer.de/), where any individual can register, create an area, invite others to join, and allow users to upload and download files. The assessment process requires that students have to put their poster, citizenship, and website information onto the shared area.

The use of the interactive whiteboard

The majority of our mathematics students are placed in at least one school where they will be able to use an interactive whiteboard. We therefore require, as part of the assessment process, that they produce an original interactive whiteboard resource, of at least 10 pages, for a one-hour lesson together with an appropriate lesson plan, and place both parts on the BSCW site. The software is on the CD-ROM, and we provide sessions on how to useit.

Spreadsheet skills

At the start of the course all the mathematics students already have reasonable personal spreadsheet skills. Therefore to challenge them we require that they make an interactive worksheet in Excel. This is a file that provides an activity for pupils and then offers feedback. Typically these files use: "if" conditions, to set up automatic checking of answers; conditional formatting, allowing automated coloured responses; "macros", to clear answers and set up new questions; and scroll bars, to change parameters. Once completed the interactive worksheet has to be tried in school with pupils. This then has to be written up, with the report and file placed on the BSCW site. Almost always students report success with the interactive worksheet, indicating that it motivates pupils and supports understanding. Occasionally students show pupils how to make such a worksheet and ask them to design one for younger pupils. A similar activity involves the use of some commercial short programmes with pupils.

The use of ICT in the teaching of mathematics

At two specific points in the course we ask students to report on their use of ICT with pupils. This involves a lesson plan, the ICT resource, any other materials used in the lesson and, most importantly, a critical review and evaluation of the lesson plan and the lesson. All these components have to be placed on the BSCW site. One session comes at the end of the first teaching practice and the other midway through the second practice, so we expect there to be a clear change of understanding as students become more experienced both generally and in terms of ICT use (Miller, 2005). 
Miller concludes that pre-service teachers need substantial guidance both on the "technical" side of ICT-rich school mathematics and on the cooperative side of the mathematics teacher education programme. Apparently, up to now, ICT is often conceived as a powerful but individualistic tool, and it will be an important task of mathematics teacher education to introduce pre-service teachers in cooperative ICT-rich activities.

\section{Studying Classroom Practice}

The mathematics classroom and the school can be considered as a social setting in which norms are created and teachers and pupils try to ensure working practices and fulfill expectations. In the context of teacher education, the relationships between student teachers and their mentors as well as between student teachers and their peers are part of this environment and contribute critically to student teachers' learning (Jaworski \& Gellert, 2003). When student teachers study classroom practice, this practice can be organised by experienced teachers, by themselves under the guidance of a mentor, or by other student teachers. A distinction needs to be made between the perspectives of someone who is teaching (or has just taught) mathematics and of an observer of this teaching practice. This 
distinction applies to situations in schools, where pre-service

teachers watch the classroom processes initiated by experienced teachers or where teachers and teacher educators observe the preservice teachers having a try in the classroom. From the perspective of the observer a detached analysis of what happens is possible, whereas the centred stance of practice requires a more intuitive grasping of situations in the classroom. Accordingly, the centred stance of teaching practitioners results, partly, in a shared generalisation of experience; outside observers, in contrast, argue on the grounds of symbolic objectives and general rules. These opposite perspectives, centred and de-centred, if not mediated tend to generate a reserved relationship that is not productive for learning from practice.

It is indeed important to overcome such opposite positioning. What is needed in order to be able to fruitfully analyse classroom practice in teacher education settings is a kind of re-centring. For that, it may first be necessary to disturb the natural grasping of classroom interaction to "perturb existing conceptions.. .of teaching and learning" (Mousley \& Sullivan, 1997, p. 32) and to fathom the subtleties of the apparently straightforward course of action, which, for instance, is documented on videotapes or audiotapes. Second, analysis should be directed away from assessment and judgement of 
what can be seen on the tapes towards a contentious or consensual

dispute of distinctions and effects. Disputes for convincing

interpretations and for metaphors that guide future lesson design

may develop a specific interpretative sense-making capacity. Briefly,

a re-centring stance aims at semiotic self-regulation (see Raeithel,

1996) between pre-service teachers, mentors, and teacher educators.

These kinds of social positioning and the consequences for pre-

service teachers' professional development are summarised in Table

\subsubsection{1:}

Table 1.1.3.1 Social positions with respect to classroom practice

\begin{tabular}{|c|c|c|c|}
\hline Social positions & Perception & Shared knowledge & Developmental effect \\
\hline $\begin{array}{l}\text { The centred stance } \\
\text { of teaching } \\
\text { practitioners }\end{array}$ & $\begin{array}{l}\text { Natural, intuitive } \\
\text { grasping of } \\
\text { situations in the } \\
\text { classroom }\end{array}$ & $\begin{array}{l}\text { Generalisation of } \\
\text { experience }\end{array}$ & $\begin{array}{l}\text { Consolidation and } \\
\text { refinement of trusted } \\
\text { and well-known } \\
\text { skills, instruments, } \\
\text { methods, etc. }\end{array}$ \\
\hline $\begin{array}{l}\text { The de-centred } \\
\text { stance of } \\
\text { observers }\end{array}$ & $\begin{array}{l}\text { Detached analysis of } \\
\text { familiar or } \\
\text { unfamiliar actions }\end{array}$ & $\begin{array}{l}\text { General rules, symbolic } \\
\text { objectives }\end{array}$ & $\begin{array}{l}\text { Description and } \\
\text { assessment of } \\
\text { classroom processes }\end{array}$ \\
\hline $\begin{array}{l}\text { The re-centring } \\
\text { stance of semiotic } \\
\text { self-regulation in } \\
\text { a group that } \\
\text { interprets teaching } \\
\text { practice }\end{array}$ & $\begin{array}{l}\text { Contentious or } \\
\text { consensual } \\
\text { dispute of the } \\
\text { central } \\
\text { distinctions and } \\
\text { effects }\end{array}$ & $\begin{array}{l}\text { Sense-making: } \\
\text { disputing } \\
\text { interpretations, using } \\
\text { metaphors as guides }\end{array}$ & $\begin{array}{l}\text { Modification or } \\
\text { corroboration of } \\
\text { approaches to } \\
\text { teaching and learning } \\
\text { and of action patterns }\end{array}$ \\
\hline
\end{tabular}

Different ways exist for overcoming the opposition of centred

and de-centred stances. Sayac (2005) organises professional

workshops, called "analysing professional practices", for pre-service

primary mathematics teachers as a cooperation of primary schools

and the Institut Universitaires de Formation des Mâtres (IUFM), in 
which pre-service teachers are prepared for their future teaching

practice. The main aim of the workshop is to allow pre-service

teachers "to get a better grasp of mathematics teaching at school,

thanks to a reflexive analysis on their own practices" (Sayac, 2005).

In order to reach a re-centring stance, Sayac has developed a scheme

for the pre-service teachers' activities:

Pre-service teachers are dispatched in groups of 4 between classes of the same cycle (pupils aging between 3 and 6 , or between 5 and 8 , or between 8 and 11) in order to conduct lessons prepared at the IUFM on a specific theme. They will each in their turn play a different part so as to understand what is at stake during a mathematics lesson:

- One of the pre-service teachers acts as the class teacher and is responsible for the lesson, both in terms of preparation (choice of contents, organisation, management) and actual performance.

- Another pre-service teacher observes the lesson from the perspective of what is being learnt (relevance of the setting, of the didactic variables, of the instructions, of the organisation and duration of the lesson etc.).

- The third pre-service teacher observes the lesson from the pupils' perspective: How did the pupils react to the setting? Were they active or passive?

- Focused or unfocused? Did they face difficulties? Of what kind? The fourth pre-service teacher observes the lesson from the teacher's perspective: How did s/he manage the lesson at its various stages? Was s/he able to take all the pupils and all their reactions into consideration? What help did s/he bring to pupils facing difficulties? Which mediations did s/he use?

An audio recording of the session can be considered to show how the lesson went, how the different actors (teacher, pupils) interacted and what the atmosphere in the classroom was like. In order to facilitate such observations and to make them more fruitful, especially at the start of the year, I sometimes give the pre-service teachers an observation chart to fill in according to the various perspectives adopted.

During the evaluation sessions back at the IUFM, the pre-service teacher who had played the part of the teacher gives an account to all the other students of the lesson as he experienced it, and comments, if need be, on the discrepancies between what had been planned and what actually happened. The various perspectives adopted by the other pre-service teachers are then compared and contrasted under the guidance of the teacher educator who has obviously been attending the lesson (Sayac, 2005). 
The evaluation sessions at the IUFM serve as the place for semiotic self-regulation between the four pre-service teachers who have directly experienced, although from different perspectives, the mathematics lesson under study, the teacher educator, and the other pre-service teachers who have been involved in the conduction and observation of other lessons. A re-centring stance is possible during these group meetings when the mediation between the pre-service teacher who has taught the lesson and the observers is successful.

Another attempt to reach a de-centring stance is made by Gellert and Krummheuer (2005). They are studying the ways shared knowledge is constructed among a group of experienced teachers, preservice teachers, and themselves as teacher educators. They start from two basic theoretical positions:

1. Every practice of mathematics teaching and learning is a locally emerging process with open ends. The course and the results of this process depend on the students' and the teacher(s)' capacities to interpret and influence the interaction in their classroom. How students and teacher(s) understand each moment of the lesson is crucial for their scope and margin to shape a lesson's course. A mathematics lesson is exactly what those involved see in it. As a consequence, the following is suggested: if students and teachers 
were able to interpret the locally emerging processes of teaching and learning differently, then a different practice of mathematics education would be possible. The broadening of teachers' interpretative resources is crucial for their professional development.

2. Interaction in everyday mathematics classes is a complex issue. Although interaction in the classroom is situated and its course is contingent upon the perception and realisation of those involved, the focus is on four dimensions that provide a structure for analyses of what happens in mathematics classes:

- Mathematical concepts, theorems, procedures, and models, which students and teachers talk about

- Arguments and argumentation patterns which students and teachers produce

- Patterns of interaction

- Forms of participation of active and silent students

According to Gellert and Krummheuer (2005), these dimensions facilitate differentiation between two opposite forms of interaction in the mathematics classroom, interactionally steady flow vs. thickened interaction. The first is characterised by fragmental argumentation, interaction patterns with inflexible role distribution, and less productive participation of all students; the second, in contrast, 
shows rather complete collectively produced arguments, flexible

roles of students, and scope for their involvement in the educational

process. These two forms provide different favourable opportunities

for student learning. From Gellert and Krummheuer's perspective,

teacher development may be seen as a path towards better

opportunities for students' learning of mathematics, that is, to

facilitate thick interactions that interrupt the interactionally steady

flow of everyday mathematics lessons.

From this theoretical point of view, Gellert and Krummheuer

organise a heterogeneous group consisting of pre-service teachers,

practising teachers, and themselves as teacher educators:

Based on these two assumptions we offered a 14-week mathematics education course, in which 5 teachers (from two primary schools, teaching 3rd and

4th grade mathematics) and 13 university students studying for a career as primary teacher took part. Participants were divided into stable subgroups of one teacher and two or three students each. The teacher and the two or three

students met one day of the week in the school of the teacher. There, students observed the interaction between the teacher and the pupils and among pupils, videotaped parts of the lessons, prepared themselves (supported by the teacher) for teaching the class and taught the class (observed by the teacher).

The whole group met one day of the week at university for what we call collaborative interpretation of classroom interaction. For each of these meetings, one subgroup selected about 15 minutes of videotaped (and transcribed) classroom interaction from the mathematics lessons in their school. The task of the whole group then was to reconstruct the interactional dimensions of the 
15-minute scene. The goal was to analyse what happened in the episode, to find markers why things went as they went, and how the course of interaction could have developed differently-eventually with optimised learning opportunities for the pupils. The analysis aimed at uncovering the contingencies of the supposed natural and seemingly inevitable course of a lesson.

Interpretation of videotaped classroom interaction is not a trivial task. If approached on the basis of common sense, videotaped scenes do not look radically unusual, and there seems nothing to be discovered under the surface. It is not before starting to scrutinise videotaped interaction systematically, that is to say using techniques for focussing on specific dimensions of the interaction, that one can see alternative paths through the possible ramifications of teacher(s)' and students' talk. For instance, some pupils' utterances that on the first view appear to show a lack of understanding of the mathematical problem to be tackled prove to be thoroughly rational, sense making and potentially helpful - they are just misplaced within the course of the arguments. In the first group meetings, we introduced three techniques for interpretation of classroom interaction: analysis of interaction, analysis of argumentation analysis, and analysis of pupils'

A heterogeneous group interpreting classroom practice from a re-centring stance can be regarded as a promising approach for bridging the divide between formal knowledge (about, in this case, the contingency of classroom interaction and how to make use of it) and the practice of classroom teaching. The importance of interaction patterns and interaction mechanisms is likely to be overlooked from the perspective of concrete teaching in schools. Gellert and Krummheuer summarise that to analyse accounts of interaction is thus a crucial practice of learning from practice. The heterogeneity of the group seems to provide support for teachers' and primary teachers' learning from and for practice, although this heterogeneity still is a rather unknown quantity within research on mathematics teacher education. 
In contrast to the two first examples discussed in this chapter,

the last example is related to the education of future secondary

mathematics teachers. It is more strongly focused on a teaching

technique: the teachers' generation of questions. It offers insight in

reflections about the issue of what teacher educators might do "to

guide pre-service teachers toward their own thinking about

questioning for mathematics understanding instead of pre-service

teachers searching for authenticated knowledge in this matter" (Rosu

\& Arvold, 2005):

The study of questioning was initiated at the beginning of the year when pre-service secondary mathematics teachers questioned their abilities to imagine and practice successful questioning for understanding in real mathematics classrooms. As a response to these concerns, we proposed the study of questioning for the next teaching experience. The study of

questioning addressed the content of the experiences in teacher education much more than prescriptions on structure and procedures of the study of questioning.

In the first stage, pre-service teachers were paired and each pair prepared a study of a specific issue in questioning. Special classes were set aside to discuss the focus questions and the design of studies. Readings enriched the discussions. Novices focused both on students' and teachers' questions in the field, and on their own practices.

For two months, we monitored and supervised pre-service teachers' studies. Electronic discussions within a learning community of pre-service teachers, and cooperating and mentor teachers prompted observations and debates in the study of questioning.

In the second stage, during their second semester student-teaching experience, each pre-service teacher, based on her/his experience with the previous semester investigations, designed a more focused study of questioning in practice. Weekly class meetings and discussions accompanied these studies (Rosu \& Arvold, 2005). 
All three examples have demonstrated that intensive and intelligent studies of classroom practice value theory and practice not as distant poles but as reflexively connected elements of knowledgeable activity. As Sayac (2005) concludes, "Educating teachers through practice and for practice should therefore take pride of place in the initial education of teachers because teachers can thus be initiated to the analysis of their own practice, using concepts developed by research in mathematics education, and this will facilitate the learning process of their future pupils". The study of classroom practice is very different from any unreflective fieldbased experience.

\section{Limitation}

A single course experience cannot, of course, create comprehensive or permanent changes in teachers' perceptions of mathematics and mathematics teaching nor will such a singular experience significantly affect teachers' classroom practice. Sullivan (1989), for instance, demonstrates how teaching newcomers, who have successfully worked with interesting activities along current approaches to mathematics education during their initial teacher education programmes and who have shown high levels of self- 
instruction shortly after having been employed. Apparently, schools seem to be very effective in integrating new teachers in the prevailing culture of the school.

However, expanding the realm of possibilities does not simply aim at fruitful yet isolated course experience. The ultimate purpose of presenting interesting examples from teacher education practice is the construction of a more reflective mathematics teacher education culture, within which teacher educators and future teachers can engage in developing and elaborating mathematically and socially sound conceptions of mathematics teaching and learning. As a matter of fact, this is not a short-term project.

A last, and critical, remark: the examples of mathematics teacher education practices presented and discussed at the study conference may, on the one hand, be regarded as the status quo of innovative developments in teacher education. On the other hand, there seems to be reason to assume that these examples, although diverse in nature, reflect a kind of occidental mainstream in mathematics teacher education research. The diversity of mathematics teacher education practices and of underlying intentions of these practices is, of course, much broader. For instance, in some places there is an ongoing discussion whether and how to include ethno-mathematical 
practices and reflections within teacher education programmes. In other places, particularly in countries of social transition and/or political transformation (at the time of writing, e.g., Venezuela, Bolivia), the request for a critical mathematics teacher education is considerably high. It is, perhaps, a negative side effect of the high quality and the institutional character of an ICMI study conference that not all developments and discussions, particularly from the periphery, can be included in conferences and official reports. 


\section{References}

Adler, J. (2001). Teaching mathematics in multilingual classrooms.

Dordrecht: Kluwer.

Alrø, H., \& Skovsmose, O. (2002). Dialogue and learning in mathematics education. Intention, reflection, critique. Dordrecht: Kluwer.

Amato, S. (2004). Improving student teachers' mathematical knowledge. Proceedings of the 10th International Congress of Mathematical Education, Copenhagen, Denmark. Available at http://www.icme-organisers.dk/taA/.

Amato, S. (2005). Improving student teachers' understanding of multiplication. Paper presented at the conference of the 15 th ICMI Study on the Professional Education and Development of Teachers of Mathematics, Á guas de Lindóia, Brazil.

Bairral, M., \& Zanette, L. (2005). Geometric learning and interaction in a virtual community of practice. Paper presented at the conference of the 15th ICMI Study on the Professional Education and Development of Teachers of Mathematics, Á guas de Lindóia, Brazil.

Bernstein, B. (1996). Pedagogy, symbolic control and identity:

Theory, research, critique. London: Taylor \& Francis. 
Bloch, I. (2005). Learning new ways of teaching from mathematical

research: Situations for mathematics teachers' education. Paper presented at the conference of the 15th ICMI Study on the Professional Education and Development of Teachers of Mathematics, Á guas de Lindóia, Brazil.

Brown, T. (1997). Mathematics education and language.

Interpreting hermeneutics and post- structuralism. Dordrecht: Kluwer.

Cobb, P., \& Bauersfeld, H. (Eds.). (1995). The emergence of mathematical meaning: Interaction in classroom cultures. Hillsdale: Lawrence Erlbaum.

da Ponte, J. P., Oliveira, H., \& Varandas, J. M. (2002). Development of pre-service mathematics teachers' professional knowledge and identity in working with information and communication technology. Journal of Mathematics Teacher Education, 5(2), 93-115.

Gadanidis, G., \& Namukasa, I. (2005). Math therapy. Paper presented at the conference of the 15th ICMI Study on the Professional Education and Development of Teachers of Mathematics, Á guas de Lindóia, Brazil.

Gellert, U., \& Krummheuer, G. (2005). Collaborative interpretation of classroom interaction: Stimulating practice by systematic 
analysis of videotaped classroom episodes. Paper presented at

the conference of the 15th ICMI Study on the Professional

Education and Development of Teachers of Mathematics, Á guas de Lindóia, Brazil.

Grevholm, B., \& Bergsten, C. (2005). The development of a professional language in mathematics teacher education. Paper presented at the conference of the 15th ICMI Study on the Professional Education and Development of Teachers of Mathematics, Á guas de Lindóia, Brazil.

Jaworski, B., \& Gellert, U. (2003). Educating new mathematics teachers: Integrating theory and practice, and the roles of practising teachers. In A. J. Bishop, M. A. Clements, C. Keitel, J. Kilpatrick, \& F. K. S. Leung (Eds.), Second international handbook of mathematics education (pp. 829-875). Dordrecht: Kluwer.

Kieran, C., Forman, E., \& Sfard, A. (Eds.). (2002). Learning discourse. Discursive approaches to research in mathematics education. Dordrecht: Kluwer.

Miller, D. (2005). An ICT-rich mathematical environment enhancing pre-service teacher education. Paper presented at the conference of the 15th ICMI Study on the Professional Education and Development of Teachers of Mathematics, Á 

guas de Lindóia, Brazil.

Mousley, J., \& Sullivan, P. (1997). Dilemmas in the professional education of mathematics teachers. In E. Pekhonen (Ed.), Proceedings of the 21st conference of the international group for the psychology of mathematics education (pp. 131-147). Lahti: University of Helsinki, Lahti Research and Training Centre.

Peretz, D. (2006). Enhancing reasoning attitudes of prospective elementary school mathematics teachers. Journal of Mathematics Teacher Education, 9(4), 381-400.

Peter-Koop, A., \& Wollring, B. (2005). Communicating “own strategies" in primary mathematics classrooms: Insights for pre-service teachers. Paper presented at the conference of the $15^{\text {th }}$ ICMI Study on the Professional Education and Development of Teachers of Mathematics, Á guas de Lindóia, Brazil.

Pimm, D. (1987). Speaking mathematically: Communication in mathematics classrooms. London: Routledge.

Proulx, J. (2005). “Objectives to work on" vs "Objectives to attain”: A challenge for mathematics teacher education curriculum? Paper presented at the conference of the 15th ICMI Study on the Professional Education and Development of Teachers of 
Mathematics, Á guas de Lindóia, Brazil.

Raeithel, A. (1996). On the ethnography of cooperative work. In

Y. Engeström, \& D. Middleton (Eds.), Cognition and communication at work (pp. 319-339). Cambridge, MA:

University Press.

Rosu, L. M., \& Arvold, B. (2005). Questioning as learning milieu in mathematics teacher education. Paper presented at the conference of the 15th ICMI Study on the Professional Education and Development of Teachers of Mathematics, Á guas de Lindóia, Brazil.

Sayac, N. (2005). A scheme for the initial education of teachers: Analysing practices during professional workshops. Paper presented at the conference of the 15th ICMI Study on the Professional Education and Development of Teachers of Mathematics, Á guas de Lindóia, Brazil.

Sullivan, P. (1989). An investigation of the impact of pre-service teacher education and other professional support on classroom practices of primary teachers. Ph.D. dissertation, Monash University, Melbourne, Australia. 